\title{
Biocompatible nickel-prussian blue@silver nanocomposites show potent antibacterial activities
}

\author{
Sudip Mukherjee ${ }^{*} \ddagger 1,2$, Sourav Das ${ }^{\ddagger}, 1,2$, Saketh Nuthi ${ }^{1}$ \& Chitta Ranjan Patra ${ }^{* *, 1,2}$ \\ ${ }^{1}$ Chemical Biology Division, CSIR-Indian Institute of Chemical Technology, Uppal Road, Tarnaka, Hyderabad 500007, Telangana \\ State, India \\ ${ }^{2}$ Academy of Scientific \& Innovative Research (AcSIR), Training \& Development Complex, CSIR Campus, CSIR Road, Taramani, \\ Chennai 600113, India \\ * Author for correspondence: sudip.mukherjee1988@gmail.com \\ ** Author for correspondence: crpatra@iict.res.in \\ Authors contributed equally
}

Aim: Silver nanoparticles have long been used as potent antibacterial agents. However, toxicity concerns of silver nanoparticles have limited their successful clinical applications. Hence, development of silver-based novel biocompatible nanomaterials for antibacterial applications is a challenging task. Materials \& methods: Accordingly, in this work, we synthesized a biocompatible silver-based nanocomposite for antibacterial applications. The nanocompostie was characterized by several analytical techniques. The nanocomposite was further tested for its cytotoxicity in cells, chicken embryo and bacteria. Results \& Conclusion: Herein, we report a simple and cost-effective method for the synthesis of nickel-prussian blue@silver nanocomposites. The nanocomposite is highly stable and shows biocompatibility observed by in vitro assay and by ex vivo chicken embryonic angiogenesis assay. The nanocomposite exhibits profound antibacterial activity toward Gram-negative (Escherichia coli) and Gram-positive (Bacillus subtillus) bacteria. The results altogether suggest the future potential applications of nickel-prussian blue@silver nanocomposite as an antibacterial agent.

Graphical abstract:

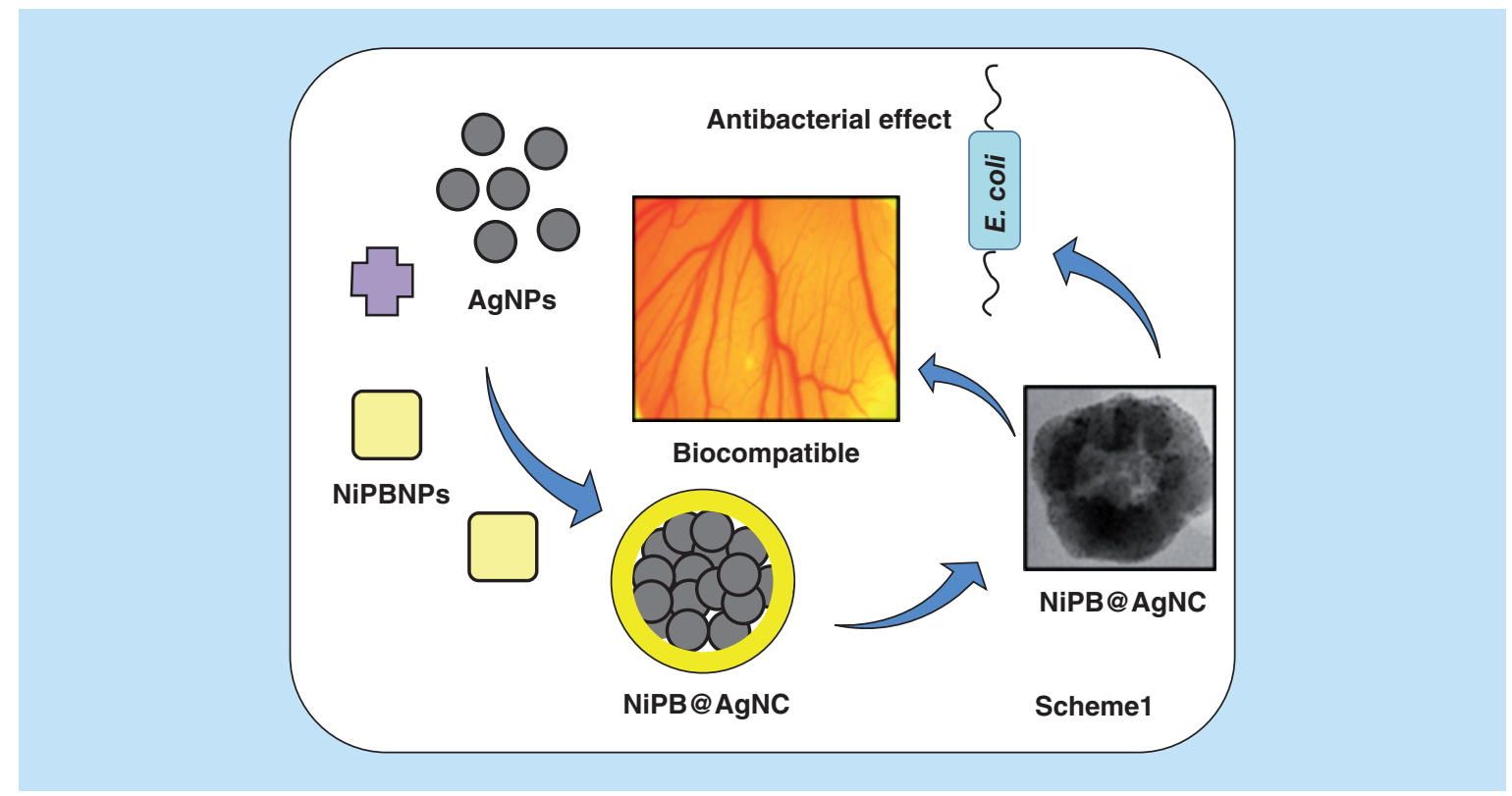

Lay abstract: Silver nanoparticles, being a potent antibacterial agent, hold enormous potential in the treatment of bacterial infections. However, serious toxicity concerns have limited their clinical use. Hence, 
design and development of biocompatible and alternative silver-based nanomedicine is urgently required. In this manuscript, we developed a biocompatible nickel-prussian blue@silver nanocomposite that demonstrates excellent antibacterial activity in both Gram-positive and Gram-negative bacteria and could be used as potent antibacterial agent in the near future.

First draft submitted: 13 April 2017; Accepted for publication: 28 June 2017; Published online: 6 September 2017

Keywords: antibacterial activity $\bullet$ biocompatible $\bullet$ CEA assay $\bullet$ nanocomposite $\bullet$ nickel-prussian blue nanoparticles - silver nanoparticles

Prussian blue nanoparticles (PBNPs) and their analogs have been used for various biomedical applications including drug delivery [1-3], imaging [4], MRI contrast agent [5], biosensors [6], photoacoustic imaging contrast agents [7] and photothermal ablation agents [8] due to their high biocompatibility, low production cost, ease of surface modification and high drug loading. Moreover, prussian blue complex (radiogardase, prussian blue in soluble form) is a US FDA-approved drug for the removal of radioactive and nonradioactive heavy metals (thallium and cesium) from the human body [9]. Low toxicity, long-term stability and low production cost would make prussian blue and its analogs ideal candidates for the treatment of various diseases [9].

Recently, bimetallic nanocomposites have gained enormous attention due to their multifunctional applications in healthcare and medicine. Presence of dual nanoparticles in nanocomposites can be useful to demonstrate multifunctional properties without hampering their own physical characteristics and applications. Very recently, scientists have synthesized core/shell nanocomposites of gold nanoparticles and prussian blue and its analog nanoparticles (Au@PB) and successfully used them for photoacoustic/CT bimodal imaging and photothermal ablation of cancer $[10,11]$. On the other hand, silver nanoparticles (AgNPs) are well established for their excellent antibacterial property [12,13]. AgNPs also have several applications (wound healing, water purification, medical application, wood preservatives, solar panels, etc.) in and out of biomedical sciences [14,15]. Several groups have previously reported the diverse biomedical applications (antibacterial activity, tissue engineering, antibioflim efficacy, photothermal therapy, photodynamic therapy, etc.) of different silver-doped nanocomposites including Ag-doped $\mathrm{TiO}_{2}$, hydroxyapatite silver nanocomposite, chitosan silver nanocomposites and so on [16-19]. With this in mind, combining the activities of AgNPs along with the prussian blue analogs could open a new dimension for successful fabrication of new multifunctional therapeutic agents. Surprisingly, there is no report of AgNP-based nanocomposites comprising prussian blue and its analogs, to the best of our knowledge.

Interestingly, various groups have reported that MRI could be utilized for in vivo tracking of bacteria as well as for characterizations of microbial infections inside human body [20,21]. Furthermore, MRI could be utilized for the imaging of tumors colonized with bacterial ferritin-expressing Escherichia coli [22]. Hence, the importance of MRI in detecting and characterizing bacterial infections is well established. In this context, we designed and developed a simple, ecofriendly and cost-effective method for the synthesis of nickel-prussian blue@silver nanocomposite (NiPB@AgNC). Selection of nickel-prussian blue (NiPB) is mainly due to the presence of its magnetic properties, which can be utilized for MRI applications [23]. Similarly, AgNPs were selected for their excellent antibacterial activity and long history of medicinal use since ancient times. Hence, the as proposed NiPB@AgNC should be useful for simultaneous detection and treatment of antimicrobial infections inside the body as a multifunctional agent. The nanocomposite was characterized by several physicochemical methods. We found that the nanocomposite is highly stable and biocompatible in nature. More interestingly, NiPB@AgNC exhibits excellent antibacterial activity toward Gram-negative (E. coli) and Gram-positive (Bacillus subtillus) bacteria. The results altogether suggest the future potential applications of NiPB@AgNC as an excellent antibacterial agent as well as a possible diagnostics agent for microbial infections.

\section{Experimental procedures}

\section{Materials}

Silver nitrate $\left(\mathrm{AgNO}_{3}\right)$, sodium borohydride $\left(\mathrm{NaBH}_{4}\right)$, potassium ferricyanide $\left.\mathrm{K}_{3}\left[\mathrm{Fe}(\mathrm{CN})_{6}\right)\right]$, nickel acetate $\left[\mathrm{Ni}(\mathrm{OAc})_{2}\right]$, Dulbecco's Modified Eagle Medium (DMEM), phosphate-buffered saline (PBS), penicillin, streptomycin, kanamycin, fetal bovine serum, 3-(4,5-dimethylthiazol-2-yl)-2,5-diphenyltetrazolium bromide (MTT) were purchased from Sigma-Aldrich Chemicals, MO, USA. All the chemicals were used without further purification. 
Stock solution preparation

$10^{-2}(\mathrm{M})$ of $\mathrm{AgNO}_{3}$ and $10^{-3}(\mathrm{M})$ of $\left.\mathrm{K}_{3}\left[\mathrm{Fe}(\mathrm{CN})_{6}\right)\right]$ and $\left[\mathrm{Ni}(\mathrm{OAc})_{2}\right]$ stock solution was prepared in sterile Millipore water and used for the synthesis of NiPB@AgNC.

Cell lines

Human lung cancer cell lines (A549) and mouse melanoma cell lines (B16F10) were purchased from American Type Culture Collection (ATCC). Human endothelial somatic hybrid cell lines (EA.hy926) were a kind gift from $S$ Oglesbee, Tissue Culture Facility, University of North Carolina, Lineberger Comprehensive Cancer Center, NC, USA, and S Chatterjee, Anna University - K B Chandrasekhar, Chennai, India.

\section{Synthesis of AgNPs}

AgNPs were synthesized by borohydride reduction methods according to the published literature [12]. Briefly, $25 \mathrm{ml}$

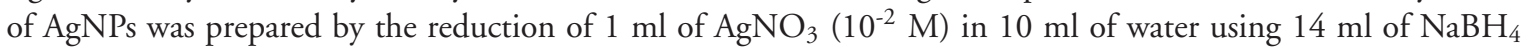
$(0.05 \mathrm{mg} / \mathrm{ml})$ for $1 \mathrm{~h}$ under continuous stirring condition.

\section{Synthesis of NiPB@AgNC}

In the first step of the reaction, $15 \mathrm{ml}$ of $10^{-3}(\mathrm{M})$ of $\left.\mathrm{K}_{3}\left[\mathrm{Fe}(\mathrm{CN})_{6}\right)\right]$ and $15 \mathrm{ml}$ of $10^{-3}(\mathrm{M})$ of $\left[\mathrm{Ni}(\mathrm{OAc})_{2}\right](1: 1$, $\mathrm{v} / \mathrm{v}$ ) were added slowly into $25 \mathrm{ml}$ of AgNPs, under vigorous stirring for $1 \mathrm{~h}$. The mixture of $\left.\mathrm{K}_{3}\left[\mathrm{Fe}(\mathrm{CN})_{6}\right)\right]$ and $\left[\mathrm{Ni}(\mathrm{OAc})_{2}\right](1: 1, \mathrm{v} / \mathrm{v})$ was repeatedly added to the resultant solution and allowed to stir for another $4 \mathrm{~h}$ in the following step to prepare yellow-colored NiPB@AgNCs.

Stability studies of NiPB@AgNC in various physiological buffers \& salines

The stability of any nanomaterials is very important before its use in healthcare. In vitro stability of NiPB@AgNC was investigated in $10 \% \mathrm{NaCl}$ solution and different PBS with different $\mathrm{pH}(6,7.4$ and 8) for 2 weeks. Briefly, $100 \mu \mathrm{l}$ of NiPB@AgNC pellet was incubated with $900 \mu \mathrm{l}$ of respective buffers and kept for 14 days. The absorbance and $\lambda_{\max }$ of the corresponding mixtures was recorded in UV-Visible spectroscopy in a time-dependent manner. Finally, we plotted the $\lambda_{\max }$ of $\mathrm{NiPB} @ \mathrm{AgNC}$ (wavelength corresponds to maximum absorbance) incubated in various buffers in different time points and compared the stability of the nanocomposites. Additionally, we measured the hydrodynamic diameter of NiPB@AgNC incubated in various buffers using dynamic light scattering (DLS: Zetasizer Ver. 6.20; Malvern-MAL100442) in different time points to check the stability of the nanocomposites.

\section{Cell culture experiments}

All cancer cell lines [A549 and B16F10] and normal cell line (EA.hy926) were cultured in DMEM media supplemented with 10\% fetal bovine serum, 0.001\% antibiotics (penicillin-streptomycin-kanamycin) and 5\% L-glutamine in a humidified $5 \% \mathrm{CO}_{2}$ incubator at $37^{\circ} \mathrm{C}$ for all in vitro biological experiments. The cells were incubated with different concentrations of NiPB@AgNC after 30 min of exposure under UV light.

\section{Cell viability test using MTT reagent}

Initially, $10 \times 10^{3}$ cells (EA.hy926, A549 and B16F10) were seeded in a 96-well plate and kept for $24 \mathrm{~h}$ in cell culture conditions (humidified $5 \% \mathrm{CO}_{2}$ incubator at $37^{\circ} \mathrm{C}$ ). Cell viability of all cancer (A549 and B16F10) and normal cells (EA.hy926) were carried out using MTT reagents after incubation of cells with different doses of NiPB@AgNC $(1,2.5,5$ and $7.5 \mu \mathrm{l} / \mathrm{ml}$ correspond to $[\mathrm{Ag}]=14,35,70$ and $105 \mu \mathrm{M}$, respectively) for $24 \mathrm{~h}$ according to our published protocol. After 24-h incubation, all treated cells were washed with PBS to remove surface-bound nanoparticles, and subsequently $100 \mu \mathrm{l}$ of MTT solution $(0.5 \mathrm{mg} / \mathrm{ml}$ in DMEM media) was added into each well for further $4 \mathrm{~h}$. After $4 \mathrm{~h}$ of incubation, the MTT solution was replaced by freshly prepared $100 \mu \mathrm{l}$ of DMSO:MeOH $(1: 1, \mathrm{v} / \mathrm{v})$ in each well and absorbance were measured at $\lambda_{\max }=575 \mathrm{~nm}$. Finally, the results were expressed as normalized percent cell viability $=([$ A570 $\{$ treated cells $\}$ - background $] /[$ A570 $\{$ untreated cells $\}$ background]) $\times 100$.

\section{Confocal microscopic analysis for fluorescent cytoskeleton \& nucleus observation}

To assess the morphology of the cells by polymerized actin, following fixation cells were analyzed by confocal microscopy. First, cells were grown on a 60-mm dishes on embedded cover slips at a density of approximately 50,000 NIH-3T3 cells/well (obtained from NCCS, Pune, India). After 18-24 h, the cells were treated with NiPB@AgNC 
(dose: $7.5 \mu \mathrm{l} / \mathrm{ml} ; 105 \mu \mathrm{M}$ with respect to silver). Following incubation for $24 \mathrm{~h}$ with the nanocomposite, the actin cytoskeleton was labeled according to the manufacturer's instructions. Briefly, cells were washed with PBS, fixed with 3.7\% formaldehyde solution for $10 \mathrm{~min}$, washed with PBS and permeabilized by $0.1 \%$ Triton X-100 in PBS. The cells were then washed with PBS and blocked with 1\% BSA for $30 \mathrm{~min}$ (to avoid nonspecific binding). After washing with PBS, the cells were incubated for $20 \mathrm{~min}$ with $5 \mu \mathrm{l}$ of Alexa Fluor 488 phalloidin (Thermo Fisher Scientific, MA, USA, Cat no. A12379) from a 200 units/ml methanolic stock. Cells were finally washed, fixed and mounted on a DAPI (4',6-diamidino-2-phenylindole) vectashield and observed under confocal imaging [laser used, 404.2, $488 \mathrm{~nm}$ in Nicon Eclipse Microscope].

\section{Chick embryonic angiogenesis assay}

The chicken embryonic angiogenesis (CEA) assay, a standard ex vivo angiogenesis assay, has been widely used to study angiogenesis and tumor invasion of different cancers [24,25]. The fertilized chicken eggs were purchased from government poultry (Directorate of Poultry Research, Hyderabad, Telangana) and incubated in an egg incubator (Southern) at $37^{\circ} \mathrm{C}$ and $60-70 \%$ relative humidity. On the fourth day of incubation, a small gap was created on the shell using forceps carefully, sterilized filter-paper discs were soaked in the NiPB@AgNC pellet $([\mathrm{Ag}]=3.5$, $7,14 \mu \mathrm{M})$. The discs were employed around the blood vessels after exposing the gap area that was covered with parafilm later. The treated and untreated eggs were incubated for next $4 \mathrm{~h}$ in the incubator. The images were captured at 0 and $4 \mathrm{~h}$ post-treatments using an LEICA camera (LEICA MC120-HD) attached to a LEICA stereomicroscope (LEICA S8AP0) at 10 megapixel magnifications.

\section{Antibacterial activity of NiPB@AgNC}

Gram-negative E. coli and Gram-positive B. subtillus growth was maintained at $37^{\circ} \mathrm{C}$ in shaker in Luria bertani broth media. The inhibition growth of E. coli and B. subtillus treated with different doses of NiPB@AgNC (1, 2.5 and $5 \mu \mathrm{l} / \mathrm{ml}$ corresponding to $[\mathrm{Ag}]=14,35$ and $70 \mu \mathrm{M}$; respectively) was monitored by multimode spectrophotometer (Varioskan) at $600 \mathrm{~nm}$ up to $6 \mathrm{~h}$. Streptomycin $(100 \mu \mathrm{g} / \mathrm{ml})$ was used as positive control antibiotics. Agar disc diffusion technique was used to evaluate antibacterial activity of E. coli and B. subtillus against nanocomposite and standard antibiotics like streptomycin $(100 \mu \mathrm{g} / \mathrm{ml})$ and penicillin $(100 \mu \mathrm{g} / \mathrm{ml})$ by measuring the inhibitory zone.

\section{Release of silver ions from NiPB@AgNC in PBS}

Release of silver ions from nanocomposite was determined using inductively coupled plasma optical emission spectrometry (ICP-OES) analysis. Initially, $500 \mu \mathrm{l}$ of the ash yellow pellet of NiPB@AgNC was obtained after centrifugation of $50 \mathrm{ml}$ of reaction mixture at 17,700 r.p.m. $15^{\circ} \mathrm{C}$ for $40 \mathrm{~min} .100 \mu \mathrm{l}$ of the pellet of the nanocomposite was incubated with $900 \mu \mathrm{l}$ of PBS ( $\mathrm{pH} 7.4$ ) and kept for different time points (0-48 h). After each time point, the mixture was mixed with $20 \mathrm{ml}$ of Milli-Q water and the solution was ultracentrifuged at 24,000 r.p.m. for $1 \mathrm{~h}$ at $20^{\circ} \mathrm{C}$. The supernatant of each solution was collected and further submitted to ICP-OES analysis for the measurement of released silver content.

\section{Characterization techniques}

The as-synthesized nanocomposite was thoroughly characterized by several physicochemical techniques. Initially, $50 \mathrm{ml}$ of NiPB@AgNC (obtained after second step of reaction) was centrifuged for $40 \mathrm{~min}$ at 17,700 r.p.m. at $15^{\circ} \mathrm{C}$ using ultracentrifuge (Thermo Fisher Scientific, Sorvall-WX ultra 100). The intense loose ash yellow-colored pellet obtained after centrifugation was used for further characterizations and cell viability studies and antibacterial studies. The absorbance, crystallinity and purity of NiPB@AgNC were monitored by UV-Visible spectroscopy (JASCO dual-beam spectrophotometer [Model V-570]) and x-ray diffraction (XRD) analysis using Bruker AXS D8 Advance Powder $x$-ray diffractometer $(\mathrm{CuK} \alpha \lambda=1.5406 \AA$ radiation), respectively. The size, morphology and surface charge (zeta potential) were determined by transmission electron microscopy (TEM: FEI Tecnai F12, Philips Electron Optics, Eindhoven, Holland) and DLS, respectively. ICP-OES [(iCAP-6500 DUO), Thermo Fisher Scientific, Cambridge, UK] was used for the determination of silver, nickel and iron in the loose pellet.

\section{Results \& discussion}

The synthesis of NiPB@AgNCs was carried out by simple addition of freshly prepared AgNPs with the mixture of equal volume of $\left.\mathrm{K}_{3}\left[\mathrm{Fe}(\mathrm{CN})_{6}\right)\right]\left[10^{-3}(\mathrm{M})\right]$ and $\left[\mathrm{Ni}(\mathrm{OAc})_{2}\right]\left[10^{-3}(\mathrm{M})\right]$. Initially, $\mathrm{AgNPs}$ were synthesized by borohydride reduction methods as the published literature [12]. AgNPs were prepared by the reduction of $\mathrm{AgNO}_{3}$ 


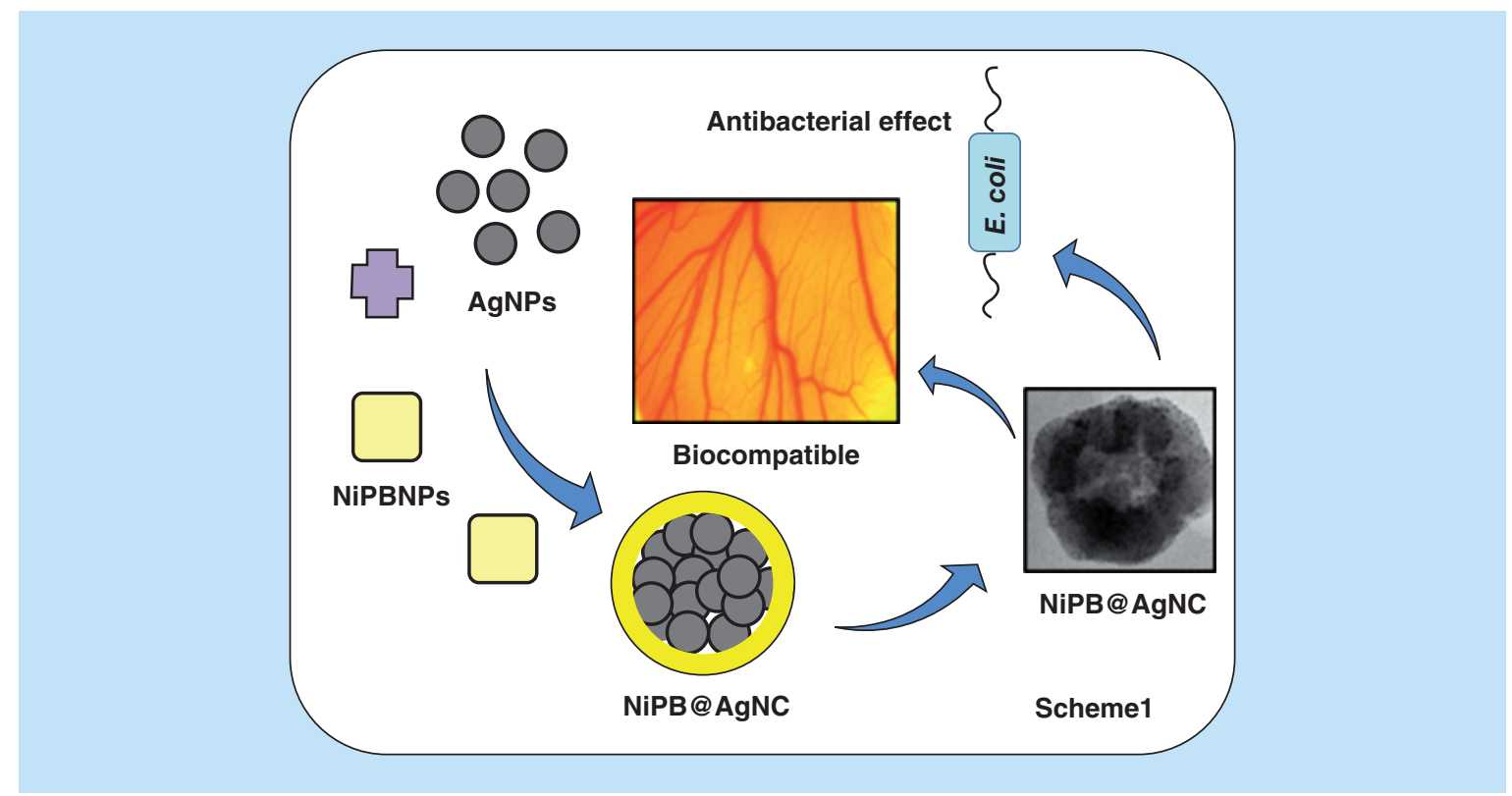

Figure 1. Schematic representation of the synthesis, characterization and antibacterial application of nickel-prussian blue@silver nanocomposite.

using $\mathrm{NaBH}_{4}$ as a reducing agent for $1 \mathrm{~h}$ under continuous stirring condition. In order to synthesize NiPB@AgNC, $15 \mathrm{ml}$ of each $10^{-3}(\mathrm{M})$ of $\left.\mathrm{K}_{3}\left[\mathrm{Fe}(\mathrm{CN})_{6}\right)\right]$ and $\left[\mathrm{Ni}(\mathrm{OAc})_{2}\right](1: 1, \mathrm{v} / \mathrm{v})$ was added slowly into AgNPs $(25 \mathrm{ml})$, under vigorous stirring for $1 \mathrm{~h}$ in the first step of the reaction. The mixture of $\left.\mathrm{K}_{3}\left[\mathrm{Fe}(\mathrm{CN})_{6}\right)\right]$ and $\left[\mathrm{Ni}(\mathrm{OAc})_{2}\right](1: 1, \mathrm{v} / \mathrm{v})$ was further added to the resultant solution for another $4 \mathrm{~h}$ to obtain intense yellow-colored NiPB@AgNCs. The addition of the mixture of equal volume of $\left.\mathrm{K}_{3}\left[\mathrm{Fe}(\mathrm{CN})_{6}\right)\right]$ and $\left[\mathrm{Ni}(\mathrm{OAc})_{2}\right]$ generates in situ double-layer coating of NiPBNPs, which acts mostly as the outer framework of NiPB@AgNC. The NiPB@AgNC was characterized by several physicochemical techniques and found to be biocompatible in nature. Furthermore, NiPB@AgNC was utilized for antibacterial applications against Gram-negative (E. coli) and Gram-positive (B. subtillus) bacteria. The overall synthesis, characterization and antibacterial application for NiPB@AgNC is schematically represented in Figure 1.

\section{UV-visible spectroscopy}

UV-visible spectroscopy was used to monitor the formation of NiPB@AgNC. Figure 2A shows the UV-visible spectrum of $\mathrm{K}_{3} \mathrm{Fe}(\mathrm{CN})_{6}$, naked AgNPs and NiPB@AgNCs obtained at first and second step of reaction (NiPB@AgNC-1 and NiPB@AgNC-2). The absorbance of NiPB@AgNC-1 and NiPB@AgNC-2 was monitored at $\lambda_{\max }$ approximately $410-415 \mathrm{~nm}$ indicating the possibility of formation of NiPB@AgNCs, which differs from the UV spectrum of $\mathrm{K}_{3} \mathrm{Fe}(\mathrm{CN})_{6}$ and $\mathrm{AgNPs}$ (Figure 2A). The absorbance intensity of NiPB@AgNC-2 is more compared with NiPB@AgNC-1, indicating the higher concentration of NiPBNPs after second step (Figure 2A). Figure 2B shows the optical images of the color of the $\left.\mathrm{K}_{3}\left[\mathrm{Fe}(\mathrm{CN})_{6}\right)\right]$ (light yellow), AgNPs (intense ash), NiPB@AgNC-1 (ash yellow) and NiPB@AgNC-2 (intense yellow), respectively, which emulate the plausible stepwise formation of nanocomposites.

\section{XRD spectroscopy}

The crystal structure of NiPB@AgNC and NiPBNPs was identified by XRD analysis (Figure 2C \& D). The diffraction peaks observed for both NiPB@AgNC and NiPBNPs at 200, 220, 400, 420, 440, 600 and 620 indicate face-centered cubic $(\mathrm{Fm}-3 \mathrm{~m})$ crystalline lattice structure [26,27] (Figure 2C \& D). This result corroborates with the XRD pattern of well-established prussian blue-based nanoparticles and nanocomposites [26,27]. However, we did not find any separate diffraction peaks for AgNPs in the XRD spectra of NiPB@AgNC. This is probably due to the double-layer thick coating of NiPBNPs on AgNPs that mask the indicative peaks of AgNPs in the XRD spectra of 
NiPB@AgNC. This also might be due to the poor crystallinity of AgNPs [28]. XRD results further reveal that there is no change of crystal structure of basic moiety (NiPBNPs) after formation of the nanocomposites.

Size, shape \& morphology analysis

In order to find out the size and morphology of nanoparticles and nanocomposite (NiPB@AgNC), TEM analysis was carried out. Figure 2E shows the TEM images of NiPBNPs. TEM images of NiPBNPs show the cubic shape with size range approximately 50-75 nm, whereas AgNPs show mainly spherical shaped with size range of 2040 nm (data not shown) [12]. On the other hand, the TEM images of NiPB@AgNC show nice spherical bimetallic nanocomposite structures with the size range of approximately 100-120 nm, which are ideal for the biomedical applications (Figure 2F). The DLS method was employed to calculate the hydrodynamic radii of nanocomposite. Result shows that the hydrodynamic diameter of NiPB@AgNC is approximately $162 \pm 5.2 \mathrm{~nm}$ (Figure 2G). Again, the surface charge or zeta potential $(\xi)$ is a crucial parameter for the dispersion or colloidal stability of nanoparticles. The size of the nanocomposite obtained from DLS is slightly higher compared with size obtained from TEM. DLS studies give an idea about the hydrodynamic diameter of any nanoparticles, which includes the association of water other molecules, whereas TEM shows the exact size of nanoparticles excluding the surface-attached molecules. The $\xi$ value of NiPB@AgNC is highly negative $(-27.1 \pm 4.34 \mathrm{mV})$, indicating exceptional stability due to high-repulsive surface negative charge (Figure $2 \mathrm{H})$.

\section{Fourier transformed infrared spectroscopy}

The peak at $2098 \mathrm{~cm}^{-1}$ in Fourier transformed infrared (FTIR) spectrum of NiPB@AgNC is indicating the presence of $\mathrm{C} \equiv \mathrm{N}$ stretching frequency (Figure 3A) [29]. The lower stretching frequency of $\mathrm{C} \equiv \mathrm{N}$ might occur due to the interaction of nickel with cyanide $(\mathrm{C} \equiv \mathrm{N})$ in the lattice state of NiPBNPs [3,29]. The cyanobridged complexes can easily be identified as they exhibit sharp peak at $v(\mathrm{CN})$, at 2000-2200 $\mathrm{cm}^{-1}$ [30]. The two peaks at 2098 and $2165 \mathrm{~cm}^{-1}$ arose owing to the transformation of the microstructure $\mathrm{Fe}^{2+}-\mathrm{CN}-\mathrm{Ni}^{3+}$ to the structure $\mathrm{Fe}^{3+}-\mathrm{CN}-$ $\mathrm{Ni}^{2+}$. The peaks at 2098 and $2165 \mathrm{~cm}^{-1}$ correspond to the $\nu\left(\mathrm{Fe}^{2+}-\mathrm{CN}-\mathrm{Ni}^{3+}\right)$ and $\nu\left(\mathrm{Fe}^{3+}-\mathrm{CN}-\mathrm{Ni}^{2+}\right)$, respectively. More importantly, the major part of the complex contains trivalent ion rather than the bivalent ion. The FTIR peaks at 3412 and $1611 \mathrm{~cm}^{-1}$ designated to the $\mathrm{O}-\mathrm{H}$ stretching and $\mathrm{O}-\mathrm{H}$ bending vibrations of the crystal water in the framework of the nanocomposite, respectively $[31,32]$. The stretching frequency of the -COO bond comes at $1416 \mathrm{~cm}^{-1}$, which is less intense as nickel acetate is used as one of the precursor. Meanwhile, in the low-frequency region, the peak at $595 \mathrm{~cm}^{-1}$ corresponded to the $\mathrm{Ni}-\mathrm{O}$ vibration in the $\mathrm{NiO}_{6}$ coordinate sphere $[31,33]$.

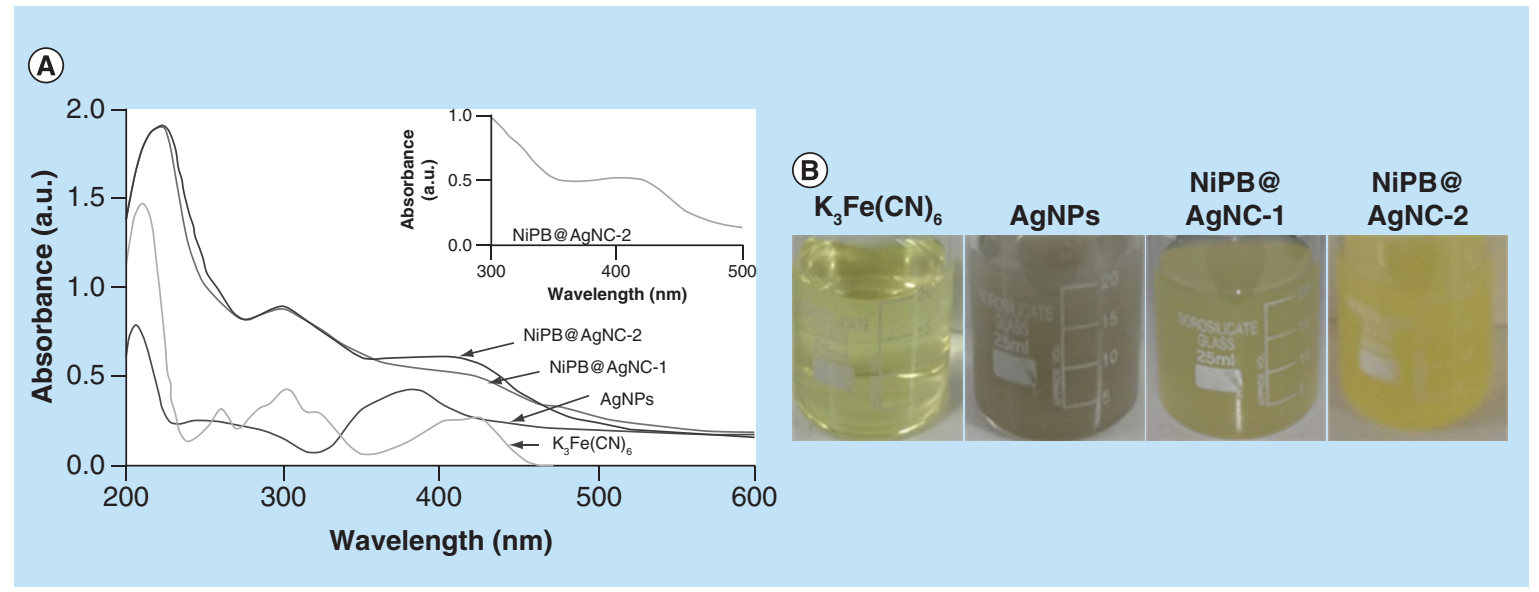

Figure 2. Characterization techniques of nanocomposite.

(A) UV-visible spectrum of $\mathrm{K}_{3} \mathrm{Fe}(\mathrm{CN})_{6}$, AgNPs, NiPB@AgNC-1 and NiPB@AgNC-2; (B) optical color images of $\mathrm{K}_{3} \mathrm{Fe}(\mathrm{CN})_{6}$, AgNPs, NiPB@AgNC-1 and NiPB@AgNC-2; (C \& D) x-ray diffraction pattern of NiPB@AgNC and NiPBNPs and (E \& F) transmission electron microscopy images of NiPB@AgNC and NiPBNPs, (G) DLS size (hydrodynamic diameter in $\mathrm{nm}$ ) and $(\mathrm{H})$ zeta potential (in $\mathrm{mV}$ ) of NiPB@AgNC.

AgNP: Silver nanoparticle; DLS: Dynamic light scattering; NiPB@AgNC: Nickel-prussian blue@silver nanocomposite; NiPBNP: Nickel-prussian blue nanoparticle. 

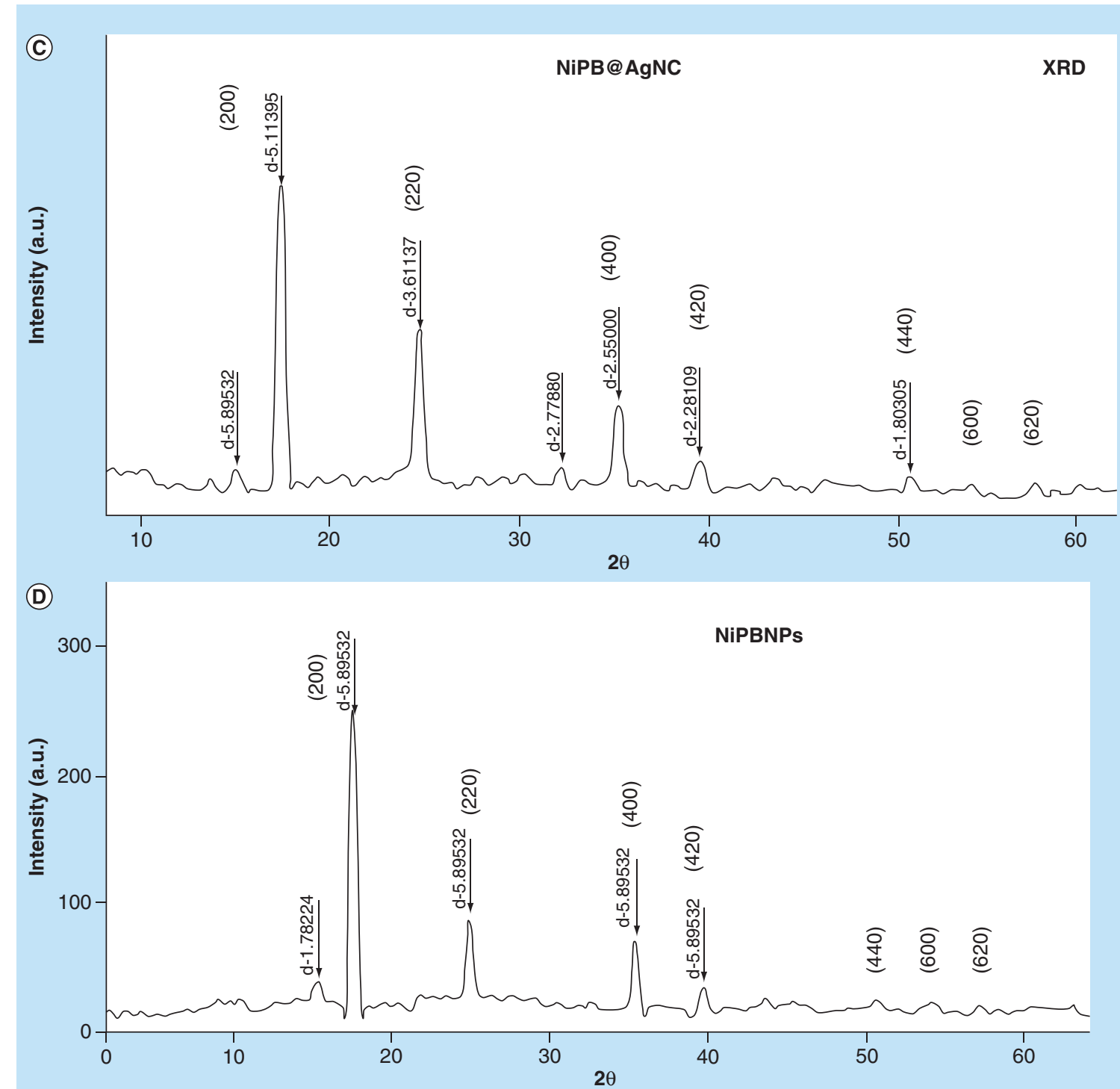

(E)

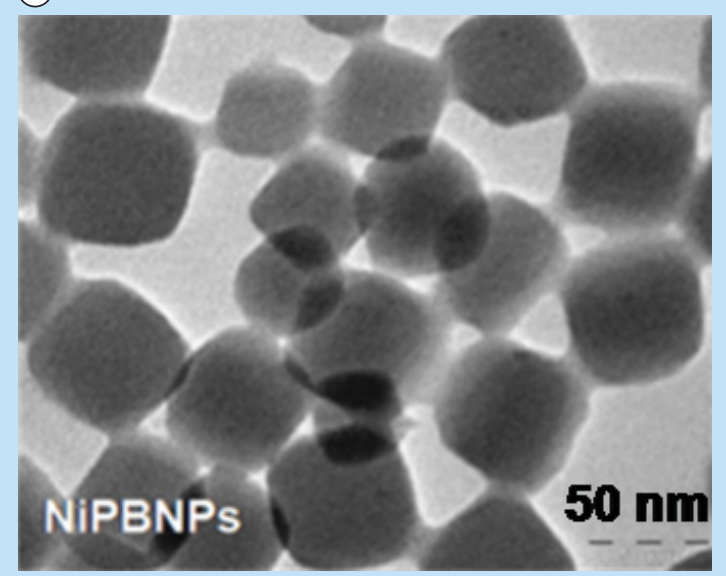

(F)

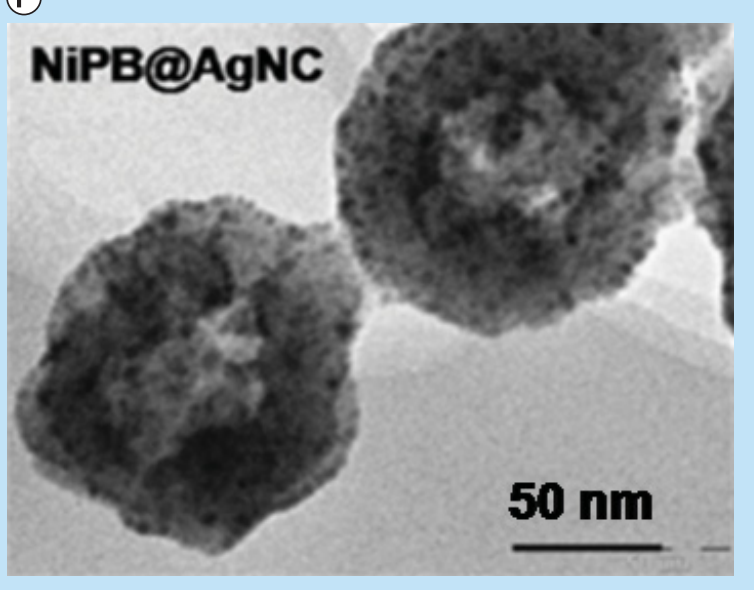

Figure 2. Characterization techniques of nanocomposite (cont.).

(A) UV-visible spectrum of $\mathrm{K}_{3} \mathrm{Fe}(\mathrm{CN})_{6}$, AgNPs, NiPB@AgNC-1 and NiPB@AgNC-2; (B) optical color images of $\mathrm{K}_{3} \mathrm{Fe}(\mathrm{CN})_{6}$, AgNPs, NiPB@AgNC-1 and NiPB@AgNC-2; (C \& D) x-ray diffraction pattern of NiPB@AgNC and NiPBNPs and (E \& F) transmission electron microscopy images of NiPB@AgNC and NiPBNPs, (G) DLS size (hydrodynamic diameter in $\mathrm{nm}$ ) and $(\mathrm{H})$ zeta potential (in $\mathrm{mV}$ ) of NiPB@AgNC.

AgNP: Silver nanoparticle; DLS: Dynamic light scattering; NiPB@AgNC: Nickel-prussian blue@silver nanocomposite; NiPBNP: Nickel-prussian blue nanoparticle. 


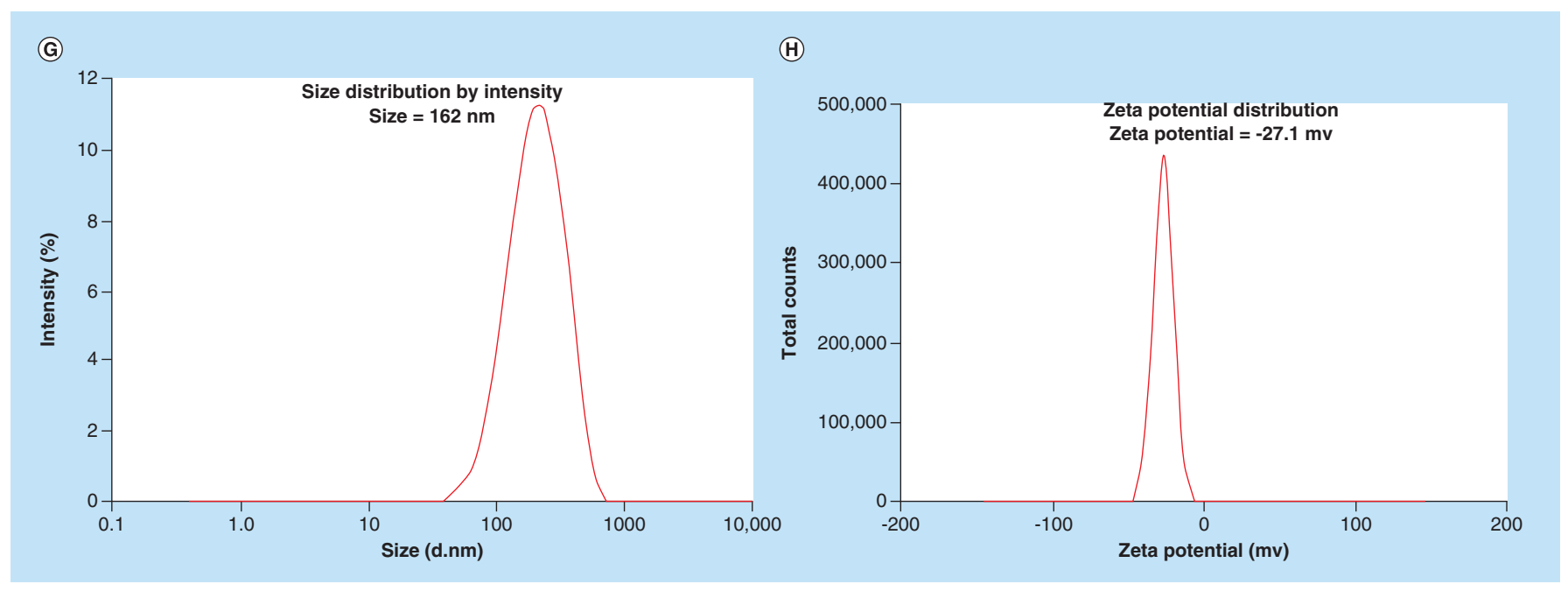

Figure 2. Characterization techniques of nanocomposite

(A) UV-visible spectrum of $\mathrm{K}_{3} \mathrm{Fe}(\mathrm{CN})_{6}, \mathrm{AgNPs}$, NiPB@AgNC-1 and NiPB@AgNC-2; (B) optical color images of $\mathrm{K}_{3} \mathrm{Fe}(\mathrm{CN})_{6}$, AgNPs, NiPB@AgNC-1 and NiPB@AgNC-2; (C \& D) x-ray diffraction pattern of NiPB@AgNC and NiPBNPs and (E \& F) transmission electron microscopy images of NiPB@AgNC and NiPBNPs, (G) DLS size (hydrodynamic diameter in $\mathrm{nm}$ ) and (H) zeta potential (in $\mathrm{mV}$ ) of NiPB@AgNC.

AgNP: Silver nanoparticle; DLS: Dynamic light scattering; NiPB@AgNC: Nickel-prussian blue@silver nanocomposite; NiPBNP: Nickel-prussian blue nanoparticle.

\section{Inductively coupled plasma optical emission spectrometer}

The concentration of metal ions (Ag: silver, Ni: nickel, Fe: iron and K: potassium) in NiPB@AgNC pellets was quantitatively estimated by ICP-OES analysis. The results show that the concentrations (in mg/l) of Ag, Ni, Fe and $\mathrm{K}$ in NiPB@AgNC are 0.30, 0.09, 0.22 and 0.07, respectively. We have selected 1, 2.5, 5 and $7.5 \mu \mathrm{l} / \mathrm{ml}$ doses for the in vitro cell viability assay and antibacterial studies. The concentrations of silver present in those corresponding doses calculated from ICP-OES analysis of NiPB@AgNC are 14, 35, 70 and $105 \mu \mathrm{M}$, respectively.

\section{Stability studies}

The stability of nanoparticles/nanocomposites is vital before its use in biomedical applications. Therefore, in vitro stability of nanocomposite was investigated in $10 \% \mathrm{NaCl}$ solution and $\mathrm{PBS}$ with different $\mathrm{pH}(6,7$ and 8$)$ for 2 weeks. Figure 3B shows that the maximum wavelength $\left(\lambda_{\max }\right)$ of NiPB@AgNC in different buffers remains almost unchanged $(<5 \mathrm{~nm})$ after 2 weeks of incubation with respect to 24-h sample, which reflects the high colloidal stability. Here, it is important to mention that salt stability is an important parameter to determine the stability and to test the aggregation properties of nanoparticles. Several groups including ours have tested the in vitro stability of AgNPs/nanocomposites in salt or saline solutions [12]. However, it is vital to mention that bare AgNPs may show formation of $\mathrm{AgCl}$ in saline solutions with time and subsequent decrease in the absorbance (sign of aggregation) of the nanoparticles that indicate instability. In our case, we do not found any decrease in the absorbance of the nanocomposites incubated with saline solutions till 14 days. This indicates the stability of NiPB@AgNC in salt solutions. This is probably due to the external double-layer thick coating of NiPBs on AgNPs, which prevents the quick dissolution of $\mathrm{AgNPs}$ and subsequent formation of $\mathrm{AgCl}$ in salt solutions.

Moreover, we measured the hydrodynamic size of NiPB@AgNC in these buffers till day 14 (Table 1). From the Table 1, it is clear that no significant change in the hydrodynamic size of NiPB@AgNC incubated in different buffers has occurred till day 14 . This directly supports the in vitro stability of NiPB@AgNC in various buffers (with $\mathrm{pH}$ 6-8) and saline solutions.

\section{In vitro cytotoxicity \& morphological analysis}

For successful application of NiPB@AgNC in biology and medicine, it is very important to check their potential cytotoxicity. In vitro cell viability assay using MTT reagents is a basic assay to evaluate the cytotoxicity of any nanomaterials or drugs. In order to check the cytotoxicity of nanocomposites, we carried out in vitro cell viability assay using MTT reagents in various cancer (A549 and B16F10) and normal cell lines (EA.hy926) for $24 \mathrm{~h}$ 


\section{(A)}

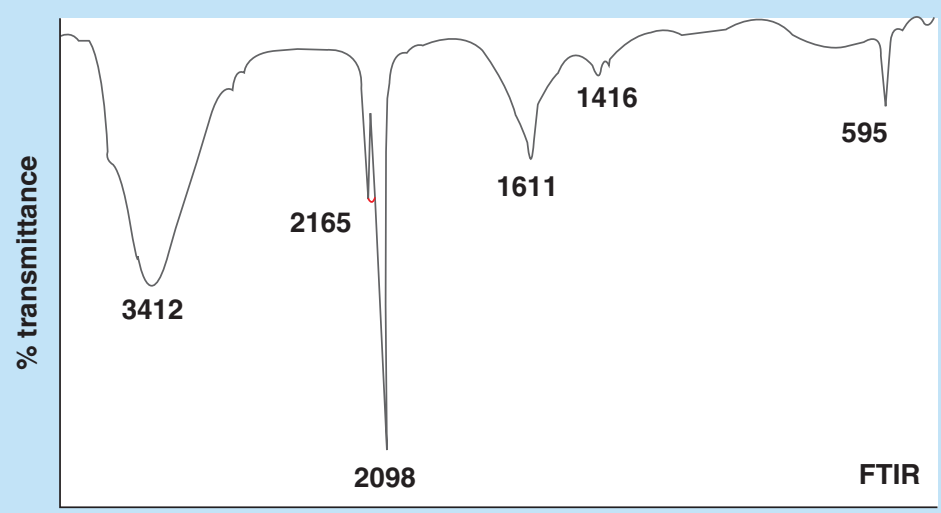

Wavenumber $\left(\mathrm{cm}^{-1}\right)$

(B)

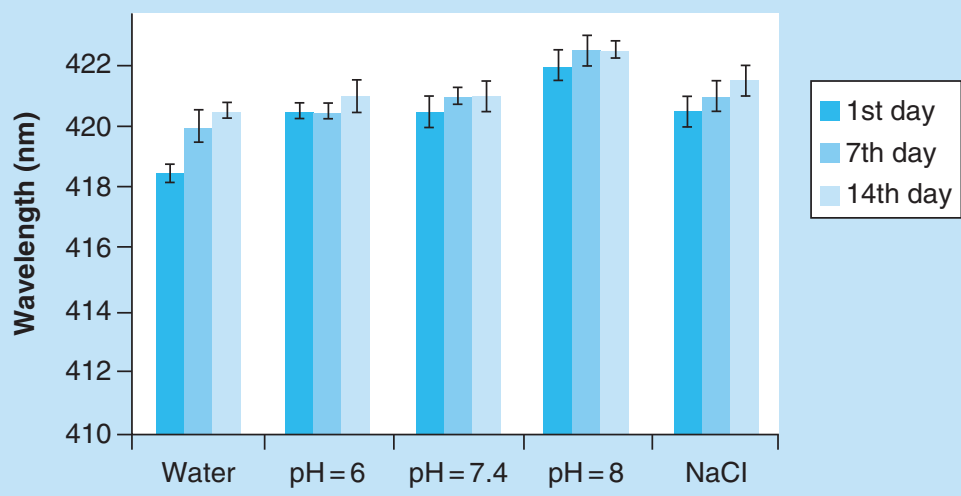

Figure 3. FTIR and stability studies.

(A) FTIR spectra of nickel-prussian blue@silver nanocomposite and (B) stability studies of nickel-prussian blue@silver nanocomposite in different physiological buffers and solutions.

FTIR: Fourier transformed infrared.

Table 1. Hydrodynamic diameter of nickel-prussian blue@silver nanocomposite in different buffers in a time-dependent manner to check the stability.

\begin{tabular}{|c|c|c|c|}
\hline Buffer solution & HD ( 0 days) in $\mathrm{nm}$ & HD (7 days) in nm & HD (14 days) in $\mathrm{nm}$ \\
\hline Water & $162 \pm 5.2$ & $163 \pm 6.9$ & $167 \pm 7.1$ \\
\hline $\mathrm{pH} 6$ & $171 \pm 7.1$ & $171 \pm 1.2$ & $175 \pm 3.5$ \\
\hline $\mathrm{pH} 7.4$ & $165 \pm 2.6$ & $168 \pm 3.9$ & $168 \pm 5.4$ \\
\hline $\mathrm{pH} 8$ & $170 \pm 5.4$ & $170 \pm 2.9$ & $171 \pm 3.2$ \\
\hline $\mathrm{NaCl}$ & $171 \pm 3.9$ & $172 \pm 4.1$ & $174 \pm 1.8$ \\
\hline
\end{tabular}

in a dose-dependent manner (Figure 4A-C). Cell viability results show that NiPB@AgNC is biocompatible in nature up to high doses of silver $([\mathrm{Ag}]=105 \mu \mathrm{M})$ in both normal as well as cancer cells (Figure 4A-C). The biocompatibility of the synthesized nanocomposite could make it useful for further biomedical applications. Our previous report demonstrates that AgNPs show cytotoxicity at $30 \mu \mathrm{M}$ dose in various normal cell lines [12]. In this case, the nanocomposite is biocompatible even at higher concentration of silver $([\mathrm{Ag}]=105 \mu \mathrm{M})$, indicating the biocompatibility of this material up to high doses. 


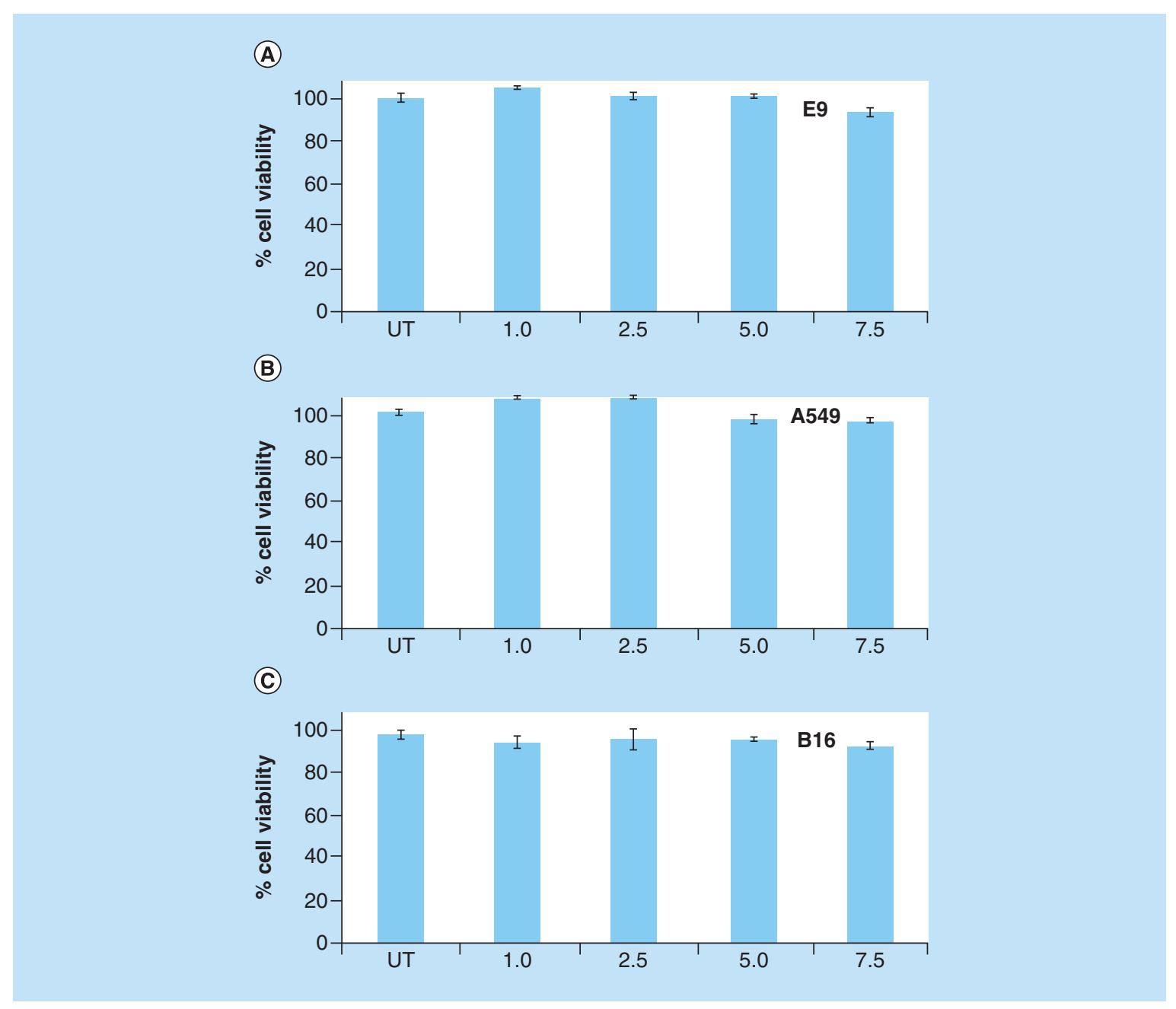

Figure 4. In vitro cytotoxicity of nanocomposite.

Cell viability assay of nickel-prussian blue@silver nanocomposite in (A) EA.hy926 (E9), (B) A549 and (C) B16F10 with different doses in for $24 \mathrm{~h}$ using 3-(4,5-Dimethylthiazol-2-yl)-2,5-diphenyltetrazolium bromide reagent. Numerical values indicate the volume of nickel-prussian blue@silver nanocomposite in $\mu \mathrm{l} / \mathrm{ml}$ (where 1, 2.5, 5 and $7.5 \mu \mathrm{l} / \mathrm{ml}$ correspond to $[\mathrm{Ag}]=14,35,70$ and $105 \mu \mathrm{M}$, respectively).

To provide further evidence of biocompatibility and visualization of cell morphology upon treatment with nanocomposites, confocal microscopy was used. The cell morphology and observation of fluorescent cytoskeleton and nucleus also give the idea of the biocompatibility of the nanoparticles or nanocomposite-treated cells. Staining of the actin filaments and nucleus give the overall structure of the cells. Results reveal that there is no change in the overall morphology of the NIH-3T3 cells even in the treatment of high doses of NiPB@AgNC $(7.5 \mu \mathrm{l} / \mathrm{ml}$; correspond to $[\mathrm{Ag}]=105 \mu \mathrm{M}$ for $24 \mathrm{~h}$ ) compared with the untreated cells (Figure $5 \mathrm{~A}-\mathrm{H}$ ). The pictures clearly show that there is no change in the actin cytoskeleton structure or presence of nuclear fragmentation even after high doses of treatment (Figure 5A-H). These results indicate the biocompatibility of nanocomposites even at high doses [34,35].

\section{CEA assay: ex vivo toxicity}

The CEA assay, a typical ex vivo angiogenesis assay, has been commonly used to study angiogenesis and ex vivo toxicity [24,25]. In order to investigate the ex vivo biocompatibility of the nanocomposite we performed the CEA assay. Figure 6 indicates the CEA assay where egg yolk was untreated control (control: Figure 6), or treated with NiPB@AgNC at different concentrations $(3.5,7$ and $14 \mu \mathrm{M})$. The incubation was done for 4 h. From the CEA data, no remarkable change in the blood vessels is found in different doses. The CEA results further support the ex 


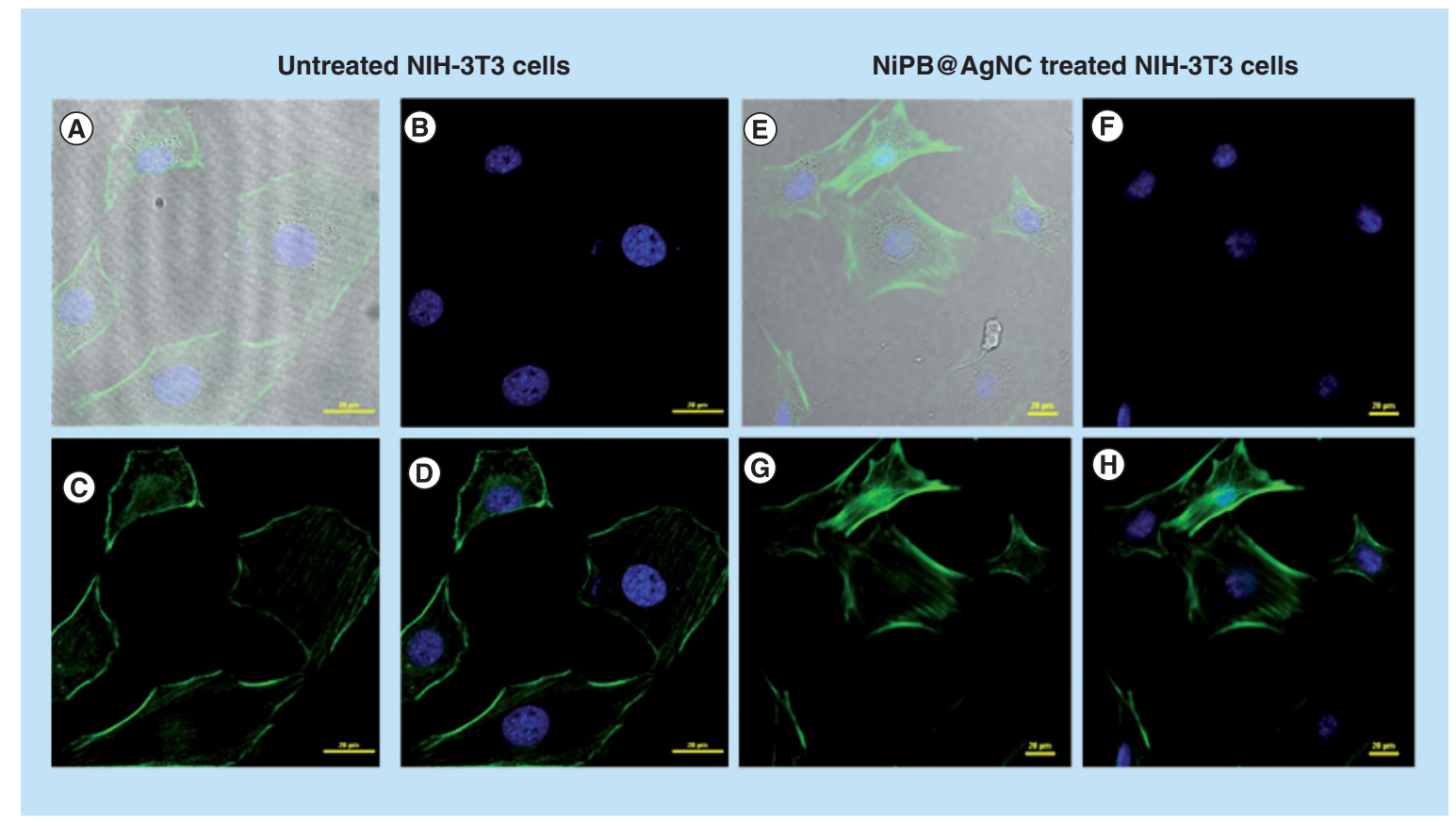

Figure 5. Confocal cell images of NIH-3T3 cells stained with DAPI and Alexa Fluor 488 phalloidin.

(A-D) NIH-3T3 cells were kept as untreated. (A) Merged images of all filters, (B) DAPI stained for nucleus of untreated cell, (C) Alexa Fluor 488 phalloidin staining for actin filaments and (D) merged images of blue and green filter of untreated cells. (E-H) Confocal images of NIH-3T3 cells were incubated with NiPB@AgNC $(7.5 \mu \mathrm{l} / \mathrm{ml}$ corresponds to $[\mathrm{Ag}]=105 \mu \mathrm{M}$ ) for $24 \mathrm{~h}$ ). (E) Merged images of all filters, (F) DAPI stained for nucleus, (G) Alexa Fluor 488 phalloidin staining for actin filaments and $(\mathrm{H})$ merged images of blue and green filter.

NiPB@AgNC: Nickel-prussian blue@silver nanocomposite.

Figure 6. Ex vivo chicken embryonic angiogenesis assay in presence of nickel-prussian blue@silver nanocomposite at different doses (with respect to silver concentration) in a time-dependent manner.

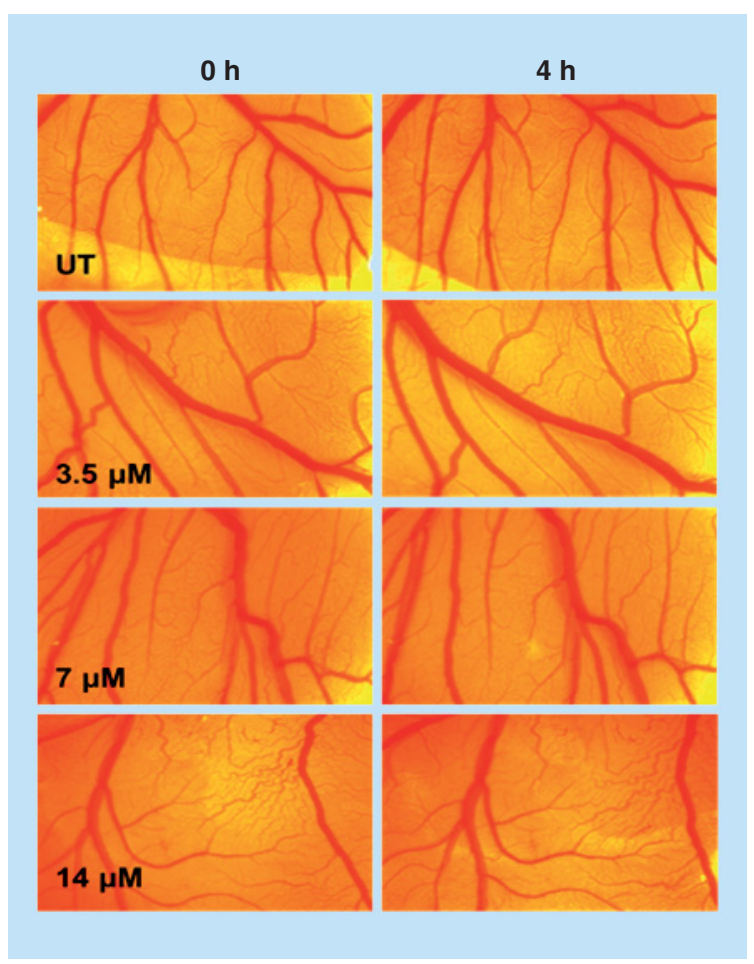




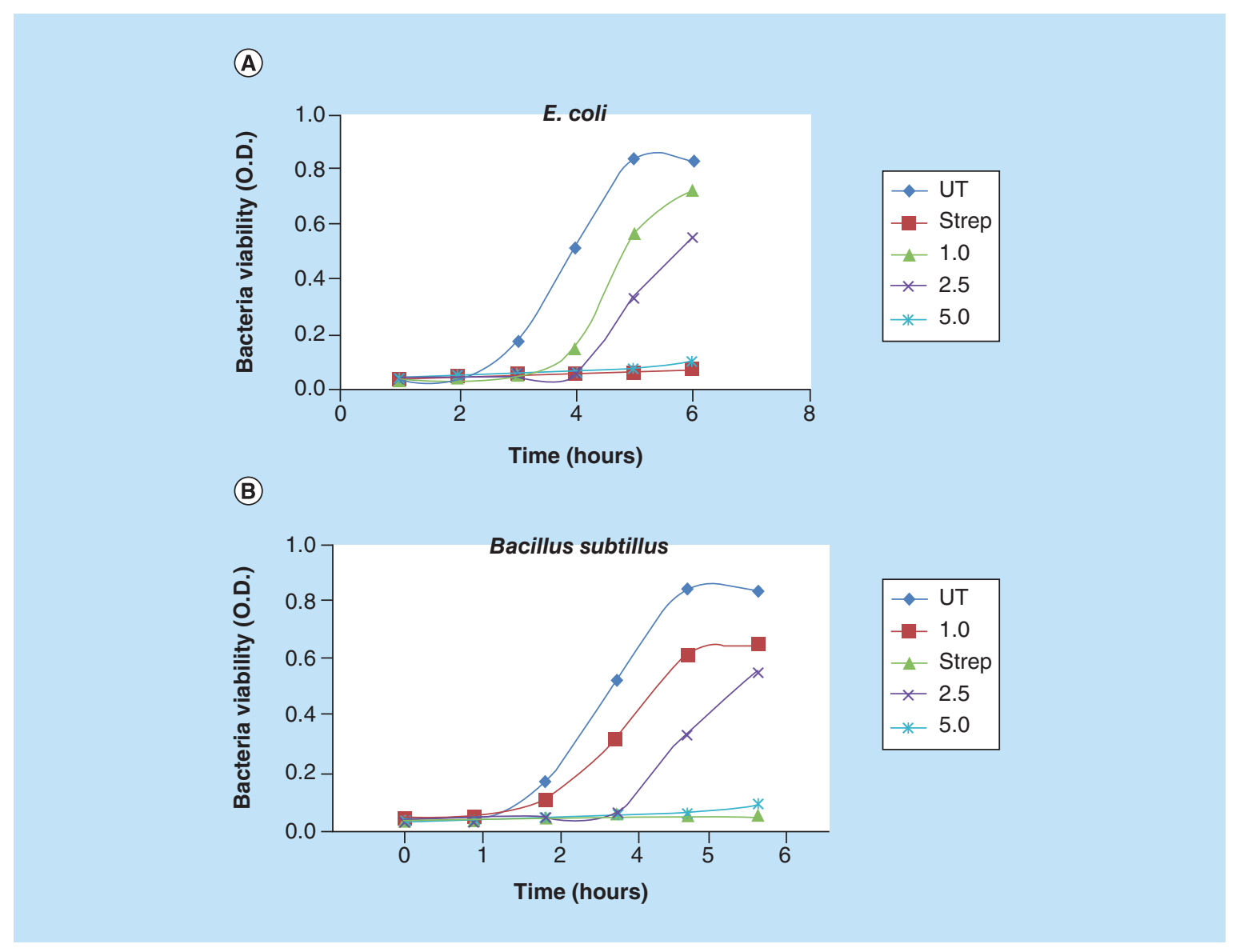

Figure 7. Antibacterial activity of nanocomposite.

Liquid growth inhibition kinetics of (A) Escherichia coli and (B) Bacillus subtillus using different volumes of nickel-prussian blue@silver nanocomposite. The numerical value indicates the volume of nickel-prussian blue@silver nanocomposite in $\mu \mathrm{l} / \mathrm{ml}$ (where 1, 2.5, $5 \mu \mathrm{l} / \mathrm{ml}$ correspond to $[\mathrm{Ag}]=14,35$ and $70 \mu \mathrm{M}$, respectively).

vivo biocompatible nature of the nanocomposite, which could be useful for the safe use of these nanomaterials in healthcare and medicine after proper preclinical study. Hence, both in vitro and ex vivo results support the nontoxic nature of NiPB@AgNC.

\section{Antibacterial activity} Growth inhibition study

Time-dependent growth of untreated bacteria (E. coli and B. Subtillus) and bacteria treated with different doses of $\mathrm{NiPB} @ \mathrm{AgNC}$ in Luria bertani broth was studied by measuring the O.D. of bacteria. Figure 7A \& B shows the graphical representation of inhibition kinetics for E. coli and B. subtillus treated with different concentrations of nanocomposite. The inhibition of growth is observed with NiPB@AgNC in a dose-dependent manner compared with untreated bacteria. Around $100 \%$ inhibition is observed at $70 \mu \mathrm{M}$ of $\mathrm{Ag}(5 \mu \mathrm{l} / \mathrm{ml}$ of NiPB@AgNC) at $6 \mathrm{~h}$, which is similar with the effects of positive-control drug streptomycin $(100 \mu \mathrm{g} / \mathrm{ml})$, indicating high therapeutic efficacy.

\section{Zone of inbibition study}

Agar diffusion disc method was employed in order to investigate the antibacterial activity of different concentration of NiPB@AgNC toward E. coli and B. subtillus. The antibacterial activity of NiPB@AgNC was compared with standard antibiotics like streptomycin $(100 \mu \mathrm{g} / \mathrm{ml})$ and penicillin $(100 \mu \mathrm{g} / \mathrm{ml})$ by measuring the zone of inhibition (Table 2, Figure 8A \& B). The results are tabulated in Table 2. Interestingly, in case of E. coli, NiPB@AgNC $($ at $[\mathrm{Ag}]=14 \mu \mathrm{M})$ shows larger inhibition zone $(\sim 20 \mathrm{~mm})$ compared with positive-control drug penicillin 
Table 2. Zone of inhibition values of nickel-prussian blue@silver nanocomposite toward Escherichia coli and Bacillus subtillus.

\begin{tabular}{|lll|}
\hline Dose of NiPB@AgNC in $\mu$ M with respect to Ag & ZOI toward $E$. coli (in mm) & ZOI toward B. subtillus (in mm) \\
\hline 14 & 20 & 16 \\
\hline 10.5 & 19 & 13 \\
\hline 7 & 18 & 11 \\
\hline 3.5 & 13 & 7 \\
\hline 1.4 & 7 & \\
\hline NiPB@AgNC: Nickel-prussian blue@silver nanocomposite; ZOI: Zone of inhibition.
\end{tabular}

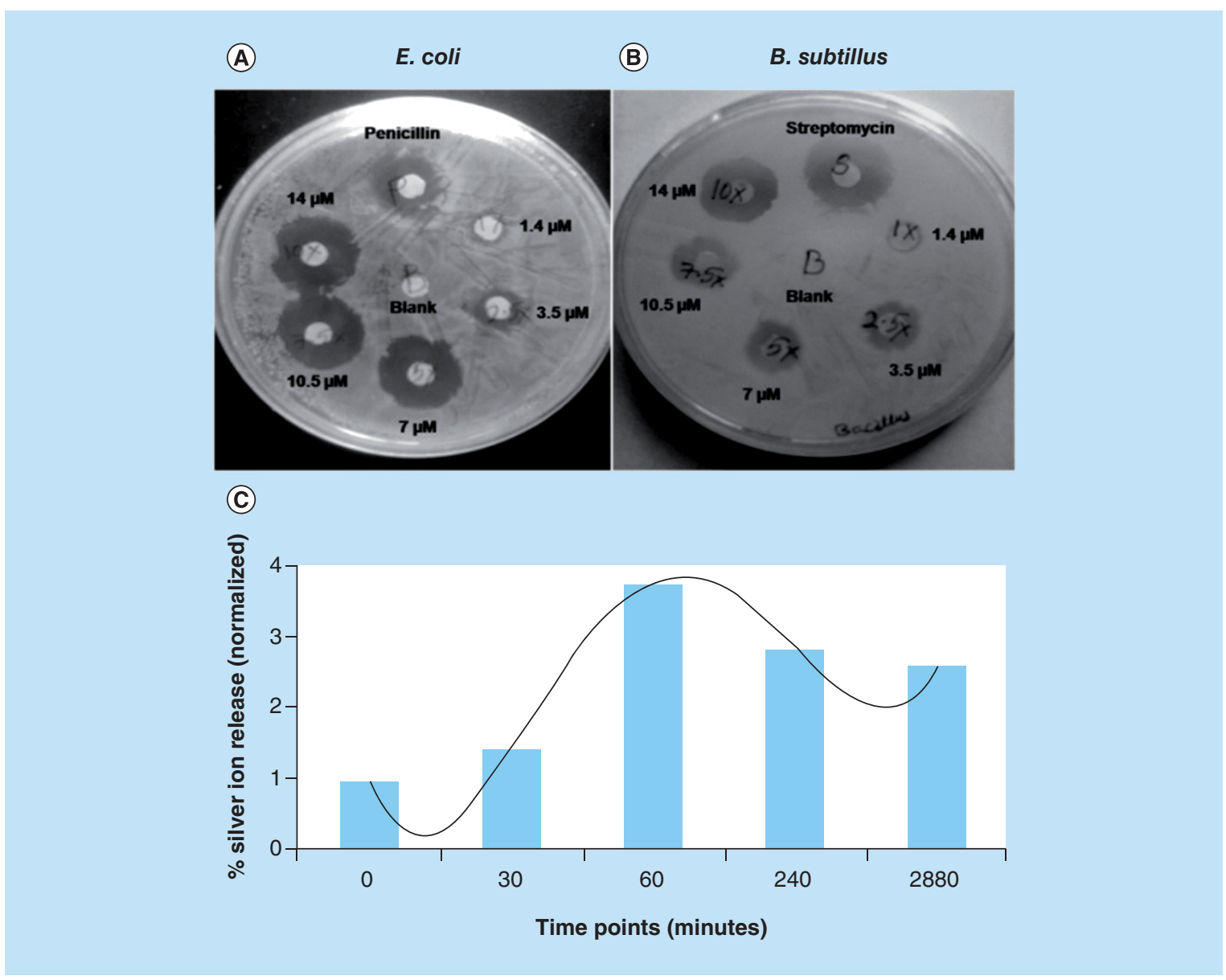

Figure 8. Zone of inhibition and silver ion release study.

Zone of inhibition of nickel-prussian blue@silver nanocomposite with different doses in (A) Escherichia coli and (B) Bacillus subtillus. Streptomycin and penicillin were kept as positive control. (C) Silver ion release kinetic study in phosphate buffer ( $\mathrm{pH}$ 7.4) using inductively coupled plasma optical emission spectrometry analysis.

( $14 \mathrm{~mm}$; Figure 8A \& B). Again, NiPB@AgNC shows almost comparable inhibition zone $(\sim 16 \mathrm{~mm})$ with standard antibiotics streptomycin $(\sim 18 \mathrm{~mm})$ in Gram-positive bacteria, B. subtillus (Figure 8A \& B). Our earlier published reports show that AgNPs exhibit around $10 \mathrm{~mm}$ of inhibition zone toward E. coli at $30 \mu \mathrm{M}$ of silver concentration [12]. Compared with earlier published reports, it is obvious that the nanocomposites exhibit twice the antibacterial activity $(\sim 20 \mathrm{~mm}$ zone of inhibition at $[\mathrm{Ag}]=14 \mu \mathrm{M})$, at half of the silver concentration compared with AgNPs. The nanocomposites in the present work thus show far superior antibacterial activity compared with AgNPs, establishing the elevated therapeutic efficacy of these materials. 
It is well established that AgNPs show excellent antibacterial activity due to mainly bacterial membrane damage or production of reactive oxygen species by $\mathrm{Ag}^{+}$ions [12]. To get a possible idea regarding the mechanism of antibacterial activity of the nanocomposites, we checked the release of silver ions in a time-dependent manner. Results show that a time-dependent release of $\mathrm{Ag}^{+}$ions from NiPB@AgNC, which get saturated after 60 min and continue to sustain release till $48 \mathrm{~h}$ (Figure $8 \mathrm{C}$ ). This sustained release of $\mathrm{Ag}^{+}$ions could be the plausible reason for the antibacterial activity of the nanocomposites in Gram-negative and Gram-positive bacteria. Recently, Lu et al. exhibited that $\mathrm{AgNPs}$ convert to $\mathrm{Ag}^{+}$and superoxide anions in presence of dissolved oxygen in a rapid manner, according to the following reaction $[36,37]$ :

AgNPs $+\mathrm{O}_{2}$ (dissolved oxygen $) \rightarrow \mathrm{Ag}^{+}$(silver ion $)+\mathrm{O}_{2} \cdot-$ (superoxide radical)

However, the release of $\mathrm{Ag}^{+}$ions from AgNPs is rapid and hence nonspecific in nature. Hence, rapid release of $\mathrm{Ag}^{+}$ may cause toxicity due to lack of targeting ability, nonspecific deposition of silver and lack of stability. However, the release of $\mathrm{Ag}^{+}$from NiPB@AgNC is much slower than AgNPs, due to double-layer coating of NiPBNPs on AgNPs. Consequently, this prevents rapid and nonspecific leakage of $\mathrm{Ag}^{+}$ions. Hence, this sustained and slow release of $\mathrm{Ag}^{+}$ions from NiPB@AgNC ensures the enhanced therapeutic efficacy (antibacterial activity) and less cytotoxicity (in normal cells). Recently, different groups including ours have demonstrated development of multifunctional nanoparticles/nanocomposites for various theranostics applications [38-40]. Together, these above results strongly support the successful fabrication of a robust nanocomposite that can be used for bacterial theranostics applications.

\section{Conclusion}

In this article, we report the synthesis of NiPB@AgNCs. The synthesis method is simple, efficient, ecofriendly and economically cheap. Physicochemical characterizations of nanocomposite show high stability. The in vitro MTT assay in normal and cancer cells demonstrate the biocompatibility nature of nanocomposite. Ex vivo CEA assay further supports the biocompatibility of the nanomaterials. Finally, the nanocomposite exhibits excellent antibacterial activity against Gram-negative (E. coli) and Gram-positive (B. subtillus) bacteria. The results altogether demonstrate the future potential applications of this newly developed nanomedicine (NiPB@AgNC) as an effective antibacterial agent.

\section{Future perspective}

These exciting data on potent antibacterial activity of highly biocompatible silver-based nanocomposites are likely to pave the way for the development of potential safer nanomedicine that can be effectively used for clinical studies. Our synthesized nanomedicine (NiPB@AgNC) is safer at higher doses compared with several commercial silverbased nanomedicines. Moreover, NiPB@AgNC demonstrates significant high therapeutic activity. This could be a game changer in the near future considering low toxicity and improved therapeutic efficacy. However, detailed and rigorous studies still need to be explored, mainly regarding its mechanistic aspects and systematic in vivo toxicity before its clinical applications. Additionally, MRI studies also need to be performed to confirm the potential diagnostic ability of NiPB@AgNC for bacterial infections.

Author contributions

S Mukherjee and CR Patra designed the overall work plan. S Mukherjee, S Das and S Nuthi conducted the studies and analyze the data. S Das arranged the references. S Mukherjee, S Das and CR Patra envisioned and wrote the manuscript.

Acknowledgements

The authors are thankful to Mass and Analytical Division, CSIR-IICT for performing ICP-OES analysis (AARF project, CSIR 12th FYP) in detection of metal content in biological samples. The authors are also thankful to Steve Oglesbee, TCF, UNC Lineberger Comprehensive Cancer Center, NC, USA and Suvro Chatterjee, AU-KBC, Chennai, India for giving permission to use of the EA.hy926 cells, respectively.

Financial \& competing interests disclosure

Dr. CR Patra is grateful to CSIR, New Delhi for generous financial support from 12th Five-Year Plan project (Advanced Drug Delivery System: CSC0302) and to DST, Nanomission, New Delhi (SR/NM/NS-1252/2013; GAP 0570) for this research. Dr. S Mukherjee and S Das are thankful to CSIR and UGC, New Delhi, respectively, for their research fellowship. The authors have no other relevant affiliations or financial involvement with any organization or entity with a financial interest in or financial conflict with the subject matter or materials discussed in the manuscript apart from those disclosed. 
No writing assistance was utilized in the production of this manuscript

\section{Ethical disclosure}

For studies involving data relating to human or animal experimental investigations, appropriate institutional review board approval has been obtained and is described within the article (for those investigators who do not have formal ethics review committees, the principles outlined in the Declaration of Helsinki have been followed).

Open access

This work is licensed under the Creative Commons Attribution 4.0 License. To view a copy of this license, visit http:// creativecommons.org/licenses/by/4.0/

Summary points

- Nickel-prussian blue@silver nanocomposite (NiPB@AgNC) has been synthesized by a simple, efficient and cost-effective method.

- NiPB@AgNC has been characterized by several analytical techniques (UV-visible spectroscopy, x-ray diffraction, dynamic light scattering and transmission electron microscopy, etc.).

- The nanocomposite is highly stable in various physiological buffers and solutions for 2 weeks.

- NiPB@AgNC is biocompatible in nature, observed by in vitro (cellular morphological analysis, cytoskeleton analysis, nucleus analysis and 3-(4,5-dimethylthiazol-2-yl)-2,5-diphenyltetrazolium bromide assay) and ex vivo chicken embryonic angiogenesis assay.

- The nanocomposite exhibits potent therapeutic efficacy (antibacterial activity) against Gram-negative (Escherichia coli) and Gram-positive (Bacillus subtillus) bacteria.

- Mechanistic studies revealed that low cytotoxicity and improved antibacterial efficacy is due to the slow and sustained release of the silver ion $\left(\mathrm{Ag}^{+}\right)$.

\section{References}

Papers of special note have been highlighted as: $\bullet$ of interest; $\bullet \bullet$ of considerable interest

1 Lian HN, Hu M, Liu CH, Yamauchi Y, Wu KC. Highly biocompatible, hollow coordination polymer nanoparticles as cisplatin carriers for efficient intracellular drug delivery. Chem. Commun. 48(42), 5151-5153 (2012).

2 Wang SJ, Chen CS, Chen LC. Prussian blue nanoparticles as nanocargoes for delivering DNA drugs to cancer cells. Sci. Technol. Adv. Mat. 14(4), 044405 (2013).

3 Mukherjee S, Rao BR, Sreedhar B, Paik P, Patra CR. Copper prussian blue analogue: investigation into multifunctional activities for biomedical applications. Chem. Commun. 51(34), 7325-7328 (2015).

4 Dumont MF, Hoffman HA, Yoon PR et al. Biofunctionalized gadolinium-containing prussian blue nanoparticles as multimodal molecular imaging agents. Bioconjug. Chem. 25(1), 129-137 (2014).

5 Mohammadreza S, Soehnlen ES, Hao J et al. Dual purpose prussian blue nanoparticles for cellular imaging and drug delivery: a new generation of T1-weighted MRI contrast and small molecule delivery agents. J. Mater. Chem. 20(25), 5251-5259 (2010).

- First ever report for the multifunctional biomedical applications of prussian blue nanoparticles.

6 Fiorito PA, Gonçales VR, Ponzio EA, de Torresi SI. Synthesis, characterization and immobilization of prussian blue nanoparticles. A potential tool for biosensing devices. Chem. Commun. 25(1), 366-368 (2005).

7 Liang X, Deng Z, Jing L et al. Prussian blue nanoparticles operate as a contrast agent for enhanced photoacoustic imaging. Chem. Commun. 49(94), 11029-11031 (2013).

8 Fu G, Liu W, Feng S, Yue X. Prussian blue nanoparticles operate as a new generation of photothermal ablation agents for cancer therapy. Chem. Commun. 48(94), 11567-11569 (2012).

9 Food and Drug Administration. Prussian blue (ferric hexacyanoferrate (II)) for treatment of internal contamination with thallium or radioactive cesium, November (2015). www.fda.gov/Drugs/EmergencyPreparedness/BioterrorismandDrugPreparedness/ucm130334.htm

10 Cheng L, Gong H, Zhu W et al. PEGylated prussian blue nanocubes as a theranostic agent for simultaneous cancer imaging and photothermal therapy. Biomaterials 35(37), 9844-9852 (2014).

11 Jing L, Liang X, Deng Z et al. Prussian blue coated gold nanoparticles for simultaneous photoacoustic/CT bimodal imaging and photothermal ablation of cancer. Biomaterials 35(22), 5814-5821 (2014).

12 Mukherjee S, Chowdhury D, Kotcherlakota R et al. Potential theranostics application of bio-synthesized silver nanoparticles (4-in-1 system). Theranostics 4(3), 316-335 (2014).

-. First ever report from our group highlighting 4-in-1 applications of silver nanoparticles. 
13 Gurunathan S, Lee KJ, Kalishwaralal K, Sheikpranbabu S, Vaidyanathan R, Eom SH. Antiangiogenic properties of silver nanoparticles. Biomaterials 30(31), 6341-6350 (2009).

14 Chaloupka K, Malam Y, Seifalian AM. Nanosilver as a new generation of nanoproduct in biomedical applications. Trends Biotechnol. 28(11), 580-588 (2010).

15 Mukherjee S, Patra CR. Biologically synthesized metal nanoparticles: recent advancement and future perspectives in cancer theranostics. Future Science OA. doi:10.4155/fsoa-2017-0035 (2017) (Epub ahead of print).

16 Deshmukh KR, Ramanan SR, Kowshik M. Low temperature processed biocompatible AgHAp nanoparticles with antibiofilm efficacy for tissue engineering applications. J. Sol-Gel Sci. Technol. 80(3), 738-747 (2016).

17 Jadalannagari S, Deshmukh KR, Ramanan SR, Kowshik M. Antimicrobial activity of hemocompatible silver doped hydroxyapatite nanoparticles synthesized by modified sol-gel technique. Appl. Nanosci. 4(2), 133-141 (2014).

18 Wei D, Sun W, Qian W, Ye Y, Ma X. The synthesis of chitosan-based silver nanoparticles and their antibacterial activity. Carbohydr. Res. 344(17), 2375-2382 (2009).

19 Tan X, Wang J, Pang X et al. Indocyanine green-loaded silver nanoparticle@polyaniline core/shell theranostic nanocomposites for photoacoustic/near-infrared fluorescence imaging-guided and single-light triggered photothermal and photodynamic therapy. ACS Appl. Mater. Interfaces 8(51), 34991-35003 (2016).

20 Hoerr V, Faber C. Magnetic resonance imaging characterization of microbial infections. J. Pharm. Biomed. Anal. 93, 136-146 (2014).

21 Hoerr V, Tuchscherr L, Hüve J et al. Bacteria tracking by in vivo magnetic resonance imaging. BMC Biol. 11(1), 63-76 (2013).

22 Hill PJ, Stritzker J, Scadeng M et al. Magnetic resonance imaging of tumors colonized with bacterial ferritin-expressing Escherichia coli. PLoS ONE 6(10), e25409 (2011).

23 Maurin-Pasturel G, Long J, Guari Y et al. Nanosized heterostructures of Au@Prussian blue analogues: towards multifunctionality at the nanoscale. Angew. Chem. Int. Ed. Engl. 53(15), 3872-3876 (2014).

- Highlights the use of Ni-prussian blue nanoparticles as an MRI agent.

24 Lokman NA, Elder AS, Ricciardelli C, Oehler MK. Chick chorioallantoic membrane (CAM) assay as an in vivo model to study the effect of newly identified molecules on ovarian cancer invasion and metastasis. Int. J. Mol. Sci. 13(8), 9959-9970 (2012).

25 Mukherjee S, Sriram P, Barui AK et al. Graphene oxides show angiogenic properties. Adv. Healthc. Mater. 4(11), 1722-1732 (2015).

26 Wu XY, Deng WW, Qian JF, Cao YL, Ai XP, Yang HX. Single-crystal FeFe $(\mathrm{CN}) 6$ nanoparticles: a high capacity and high rate cathode for Na-ion batteries. J. Mater. Chem. A. 1(35), 10130-10134 (2013).

27 Gomes WJAS, de Oliveira C, Huguenin F. Energy harvesting by nickel prussian blue analogue electrode in neutralization and mixing entropy batteries. Langmuir 31(31), 8710-8717 (2015).

28 Chen DH, Chen CJ. Formation and characterization of Au-Ag bimetallic nanoparticles in water-in-oil microemulsions. J. Mater. Chem. 12(5), 1557-1562 (2002).

29 Kong Q, Chen XG, Yao JL, Xue DS. Preparation of poly(N-vinyl-2-pyrrolidone)-stabilized transition metal (Fe, Co, Ni and Cu) hexacyanoferrate nanoparticles. Nanotechnology 16(1), 164-168 (2005).

$30 \mathrm{Ng} \mathrm{CW}$, Ding J, Shi Y. Structure and magnetic properties of copper (II) hexacyanoferrate (III) compound. J. Phys. Chem. Solids 62(4), $767-775$ (2001).

31 Shen L, Wang Z, Chen L. Prussian blue analogues $\mathrm{Mn}\left[\mathrm{Fe}(\mathrm{CN})_{6}\right]_{0.6667} \cdot \mathrm{n} \mathrm{H}_{2} \mathrm{O}$ cubes as an anode material for lithium-ion batteries. Dalton Trans. 44(38), 16746-16751 (2015).

32 Zhang XQ, Gong SW, Zhang Y et al. Prussian blue modified iron oxide magnetic nanoparticles and their high peroxidase-like activity. J. Mater. Chem. 20(24), 5110-5116 (2010).

$33 \mathrm{Xu}$ J, Liu X, Chen Y, Zhou Y, Lu T, Tang Y. Platinum-cobalt alloy networks for methanol oxidation electrocatalysis. J. Mater. Chem. 22(44), 23659-23667 (2012).

34 Wu X, Tan Y, Mao H, Zhang M. Toxic effects of iron oxide nanoparticles on human umbilical vein endothelial cells. Int. J. Nanomedicine 5, 385-399 (2010).

$35 \mathrm{Lu}$ X, Qian J, Zhou $\mathrm{H}$ et al. In vitro cytotoxicity and induction of apoptosis by silica nanoparticles in human HepG2 hepatoma cells. Int. J. Nanomedicine 6, 1889-1901 (2011).

36 Lu D, Liu Q, Zhang T et al. Stable silver isotope fractionation in the natural transformation process of silver nanoparticles. Nat. Nanotechnol. 11, 682-686 (2016).

-. Landmark paper on the mechanism of natural transformation of silver nanoparticles.

37 Patra S, Mukherjee S, Barui AK et al. Green synthesis, characterization of gold and silver nanoparticles and their potential application for cancer therapeutics. Mater. Sci. Eng. C Mater. Biol. Appl. 53, 298-309 (2015).

38 Muthuraj B, Mukherjee S, Patra CR, Iyer PK. Amplified fluorescence from polyfluorene nanoparticles with dual state emission and aggregation caused red shifted emission for live cell imaging and cancer theranostics. ACS Appl. Mater. Interfaces 8(47), 32220-32229 (2016). 
39 Gaddam RR, Mukherjee S, Punugupati N et al. Facile synthesis of carbon dot and residual carbon nanobeads: Implications for ion sensing, medicinal and biological applications. Mater. Sci. Eng. C 73, 643-652 (2017).

40 Muthuraj B, Mukherjee S, Chowdhury SR, Patra CR, Iyer PK. An efficient strategy to assemble water soluble histidine-perylene diimide and graphene oxide for the detection of PPi in physiological conditions and in vitro. Biosens. Bioelectron. 89, 636-644 (2017). 
(

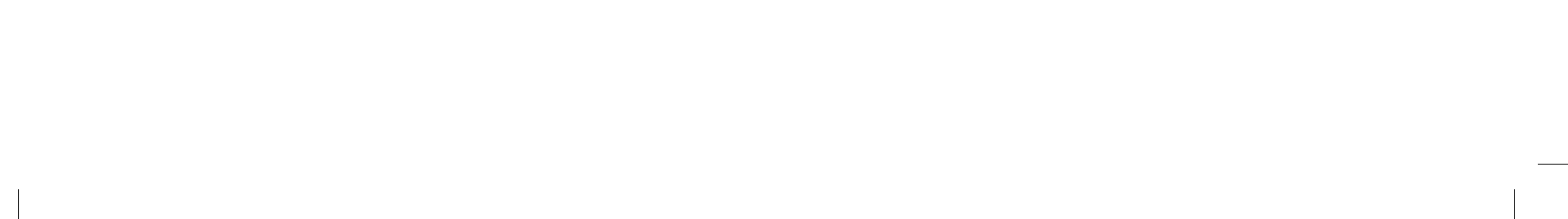

